\title{
Small scale electricity generation from a portable biomass cookstove: Prototype design and preliminary results
}

\author{
S.M. O’Shaughnessy ${ }^{\mathrm{a}, *}$, M.J. Deasy ${ }^{\mathrm{a}}$, C.E. Kinsella ${ }^{\mathrm{a}}$, J.V. Doyle ${ }^{\mathrm{b}}$, A.J. Robinson ${ }^{\mathrm{a}, *}$ \\ ${ }^{a}$ Department of Mechanical \& Manufacturing Engineering, Parsons Building, Trinity College, Dublin 2, Ireland \\ ${ }^{\mathrm{b}}$ Concern Universal Malawi, 21 Link Road, Namiwawa, P.O. Box 1535, Blantyre, Malawi
}

\section{H I G H L I G H T S}

- We have integrated a thermoelectric generator with a cooking stove.

- The device has been deployed into a village in rural Malawi for up to 3 months.

- The stoves are equipped with temperature and power data logging equipment.

- Users have already charged mobile phones, lights and radios from the stove generator.

- Data loggers will provide stove usage and power usage data.

\section{A R T I C L E I N F O}

\section{Article history:}

Received 20 March 2012

Received in revised form 20 June 2012

Accepted 20 July 2012

Available online $\mathrm{xxxx}$

\section{Keywords:}

Biomass

Cookstove

Thermoelectric

Electricity generation

Lighting

Phone charging

\begin{abstract}
A B S T R A C T
The World Health Organisation estimates that over $20 \%$ of the global population ( $\sim 1.4$ billion people) lack access to electricity. Furthermore, $40 \%$ of the global population ( $\sim 2.7$ billion people) rely on the traditional use of biomass for cooking (WHO 2011, OEDC/IEA, 2010). This study details the development of a prototype electrical generator for portable stoves commonly in use in the developing world. This generator is capable of delivering small amounts of off-grid electricity. Power is generated using the thermoelectric effect. A single thermoelectric module is utilised to convert a small portion of heat from the stove to electricity. The electricity produced is used to charge a single $3.3 \mathrm{~V}$ lithium-iron phosphate battery and drive a low power fan, as well as some other auxiliary features. The airflow produced by the fan is used in conjunction with a commercially available heat pipe heat sink to maintain an adequate temperature difference across the thermoelectric module. From experiments in the laboratory, a maximum TEG power output of $5.9 \mathrm{~W}$ has been obtained. On average, $3 \mathrm{Wh}$ of energy was stored in a battery during a typical $1 \mathrm{~h}$ long burn. Three $1 \mathrm{~h}$ long burns produced sufficient energy to fully charge the battery. The performance of the electricity generating cooking stove has subsequently been tested in Malawi using locally sourced fuel and fire stoking methods.
\end{abstract}

(c) 2012 Elsevier Ltd. All rights reserved.

\section{Introduction}

Over 2 billion people rely on biomass as their main source of domestic energy. In rural Malawi more than $90 \%$ of people use biomass for household cooking, heating and lighting [3]. This over reliance on natural resources, unsustainable agricultural practises and population pressures have led to wood scarcity and large scale deforestation with associated negative environmental impacts. Furthermore, women and young children experience substantial smoke exposure when meals are cooked over open fires in the

\footnotetext{
* Corresponding authors. Tel.: +353 1896 1061; fax: +353 16795554 (S.M. O'Shaughnessy), tel.: +3531 896 3919; fax: +3531 6795554 (A.J. Robinson).

E-mail addresses: oshaughs@tcd.ie (S.M. O’Shaughnessy), deasym1@tcd.ie (M.J. Deasy), vincent.doyle@concern-universal.org (J.V. Doyle), arobins@tcd.ie (A.J. Robinson).
}

home due to partial combustion of fuel and poor ventilation. Exposure to smoke from traditional cookstoves and open fires is a major threat to health, ranking 10th in the WHO comparative risk assessment for the global burden of disease and responsible for 1.9 million premature deaths (41 million disability adjusted life years) annually [4].

A large proportion ( $\sim 1.4$ billion) of those people who rely on biomass for cooking also lack access to grid electricity, with $85 \%$ of those people living in rural areas [1,2]. For those who can afford it, lighting is derived from a variety of sources, including but not limited to kerosene, diesel, propane, biomass and candles [5]. Technologies that 'burn' to create light can put a significant economic burden on those who use it and it has been estimated that $\$ 40$ billion is spent on off-grid lighting annually in the developing world [6]. The incongruity is that a disproportionate level of

0306-2619/\$ - see front matter (c) 2012 Elsevier Ltd. All rights reserved. http://dx.doi.org/10.1016/j.apenergy.2012.07.032 


\section{Nomenclature}

$\begin{array}{ll}A_{p} & \text { cross-sectional area of thermoelement }\left(\mathrm{m}^{2}\right) \\ I & \text { current }(\mathrm{A}) \\ K & \text { thermal conductance }(\mathrm{W} / \mathrm{K}) \\ L & \text { length of thermoelement }(\mathrm{m}) \\ L_{c} & \text { contact layer thickness }(\mathrm{m}) \\ N & \text { number of thermoelements }(-) \\ P_{\text {elec }} & \text { electrical power }(\mathrm{W}) \\ P_{\max } & \text { maximum electrical power }(\mathrm{W}) \\ Q_{H} & \text { heat delivered to TEG hot side }(\mathrm{W}) \\ Q_{C} & \text { heat dissipated from TEG cold side }(\mathrm{W}) \\ R & \text { electrical resistance }(\Omega) \\ R_{L} & \text { load resistance }(\Omega)\end{array}$

$T_{h} \quad$ module hot side temperature (K)

$T_{c} \quad$ module cold side temperature (K)

$\Delta T \quad$ module temperature difference $(\mathrm{K})$

$V \quad$ voltage $(\mathrm{V})$

$V_{o c} \quad$ open circuit voltage $(\mathrm{V})$

$Z \quad$ figure of merit $(1 / \mathrm{K})$

$\alpha \quad$ Seebeck coefficient $(\mathrm{V} / \mathrm{K})$

$\alpha_{\text {eff }} \quad$ effective Seebeck coefficient $(\mathrm{V} / \mathrm{K})$

$\alpha_{p, n} \quad$ Seebeck coefficient of $\mathrm{p} / \mathrm{n}$ couple $(\mathrm{V} / \mathrm{K})$

$\lambda \quad$ thermal conductivity $(\mathrm{W} / \mathrm{mK})$

$\rho \quad$ electrical resistivity $(\Omega \mathrm{m})$

$R_{L} \quad$ load resistance $(\Omega)$

income is spent on inefficient fuel based technologies that produce very low grade lighting [7]. Furthermore, there are inherent negative health and environmental implications associated with fuel based lighting, such as indoor air quality and carbon dioxide production.

This project has as its technical goal the engineering of a combined efficient low cost cookstove with an integrated electrical generator to power an LED lamp and a mobile phone. The conversion technology is direct heat to electricity using an integrated thermoelectric generator (TEG).

\subsection{TEGs and stoves: prior research}

Killander and Bass [8] studied the development and testing of a prototype thermoelectric generator used in wood-fed stoves in Northern Sweden. The generator design consisted of two $\mathrm{Hi}-\mathrm{Z}$ HZ20 modules mounted on a $270 \mathrm{~mm} \times 100 \mathrm{~mm}$ aluminium heat collector plate that was placed on the outside of the stove, in a region where the local stove wall temperatures approached $300^{\circ} \mathrm{C}$. The cold side temperature was maintained via an aluminium finned heat exchanger that was cooled by a $12 \mathrm{~V}, 2.2 \mathrm{~W}$ fan mounted above it. To power the fan and also to charge four $6 \mathrm{~V}$ lead acid Exide batteries, the output voltage from the TEGs was stepped up to over $13 \mathrm{~V}$ by a DC-DC converter, thus providing a reliable $12 \mathrm{~V}$ power source. The results showed that during peak feeding times (usually in the morning) the output from the generator was about $10 \mathrm{~W}$, though this would fall to about $4-5 \mathrm{~W}$ in the afternoon as the house had heated up. The power generated was sufficient to provide some electric light and provide some TV during the night.

Mastbergen [9] investigated the integration of a thermoelectric generator with a clean cookstove named the EgoFagao. The objective was to deliver $45 \mathrm{~W}$ h of power over the course of 1 day, typically consisting of three meal periods. The power was generated from two bismuth telluride Thermonamic (TEP1-12656-0.6) 14.7 W thermoelectric modules in series. Each module was cooled by a variable power $120 \mathrm{~mm}$ diameter fan attached to aluminium heat sinks $(160 \mathrm{~mm} \times 100 \mathrm{~mm} \times 63.5 \mathrm{~mm})$. This Brazilian-made stove was deployed in Nicaragua, India and Nepal with varying results. Several cultural and technical difficulties were encountered during the field trial. The generator became loose due to thermal cycling, and the batteries failed due to incomplete charging. A second generation device was developed which incorporated improvements to the charging circuit. A life cycle analysis performed by the author highlighted that the maximum TEG temperature could not exceed $280^{\circ} \mathrm{C}$ to keep the damage to the module below $20 \%$ over 5 years. Mastbergen estimated the total cost of a generator to be $\$ 170$ in quantities of 1000 .
Champier et al. [10,11] investigated the feasibility of integrating a thermoelectric generator to generate $5-10 \mathrm{~W}$ of electricity from the waste heat in a multifunction cookstove developed by "Planète Bois" called the "Combustion Latérale Inversée Performante" (CLIP). The energy efficient mud cookstove is a large fixed stove which produces heat for cooking and hot water. The exhaust gases stream was selected as the heat source for the thermoelectric generator. An experimental rig was setup using gases to replicate the temperatures in the stove. The thermoelectric used was a bismuth telluride module from Taihuaxing Co. Ltd. (TEP1-12656-0.8) capable of producing $10.5 \mathrm{~W}$ at matched load. Two cooling methods were investigated: forced convective cooling using a fan and natural convection cooling via a water tank. Using four modules, the authors obtained between $1.7 \mathrm{~W}$ and $2.3 \mathrm{~W}$ per module at a temperature difference of $160{ }^{\circ} \mathrm{C}$ and a total of $7 \mathrm{~W}$ was generated. Champier et al. made improvements to the generator design in what was called the "TEGBios II" however the device has not yet been incorporated into a real stove to our knowledge.

Several researchers have investigated methods of low-temperature waste heat harvesting using thermoelectric generators [12-14]. However, much of the research into stove generators has been laboratory based, such as studies by Rinalde et al. [15] and Nuwayhid et al. [16,17]. To verify the performance of the generators, the heat source (the fire) is normally replaced by a controllable and constant electrically powered supply. Likewise, the cold side is typically maintained by natural or forced convection methods. Although this procedure allows the evaluation of the generators performance, the test conditions do not replicate those that would occur in the field. Therefore, in an effort to mimic the actual stove conditions, the generator in this study has been integrated into an existing biomass-fed stove. This stove is currently widely used in regions of Malawi.

\section{Objectives/scope of work}

The overarching objective of the study is to develop a thermoelectric generator system that can be retrofitted onto the chitetezo mbaula cookstove and generate and store enough electricity for evening lighting and daily phone charging.

The specific objectives of the study are to:

(1) Design the appropriate heat collecting and dissipating system to achieve the desired electrical energy storage for a typical cycle of daily meal preparation.

(2) Design a simple circuit that will facilitate battery charge control and DC to $5 \mathrm{~V}$ DC conversion.

(3) Test the stove-generator system in a controlled laboratory setting. 
(4) Test the charging characteristics of a common mobile phone and an LED based lantern.

(5) Test the generator system in Malawi using common locally sourced wood and fire stoking methods.

\section{The chitetezo mbaula cooking stove}

Since 2008 Concern Universal has worked with predominately women's groups in rural areas to produce and market over 16,850 cooking stoves in five districts in Malawi. The majority of these stoves have been produced, distributed and sold in Balaka district as part of the Msamala Sustainable Energy Programme (MSEP). Women's groups produce the stoves as an income generating activity to supplement their mainly agricultural based income. The stoves are then sold-onto middlemen who distribute them over a wider geographic coverage at a small profit. The chitetezo mbaula stoves (see Fig. 1) are widely available across Malawi and are promoted by Concern Universal and other organisations as being a better and safer alternative to the traditional three stones method of cooking.

The improved cookstoves reduce the amount of fuel wood gathered and used which in turn reduces the workload of women and young girls who have to gather and carry the wood back to the household. By reducing the amount of time spent on this task, the more fuel efficient cookstove can also lessen their risk of gender based violence and their potential vulnerability to HIV and AIDS [18], as well as reducing the risks associated with leaving children unattended for long periods of time [19]. For an example of the dangers involved whilst gathering wood, The Women's Refugee Commission provides an excellent report on the threats facing women in Darfur [20].

Cooking stoves are an important element of any rural household as they provide heat, light, and cooking, but they can have negative social and environmental consequences if they are not culturally or environmentally sensitive. When people have a vested interest in the stoves they tend to take more interest and ownership of the process but they need to be able to see and feel the short-term social, environmental and economic utility of the stoves. The chitetezo mbaula meets these criteria by providing a range of benefits to

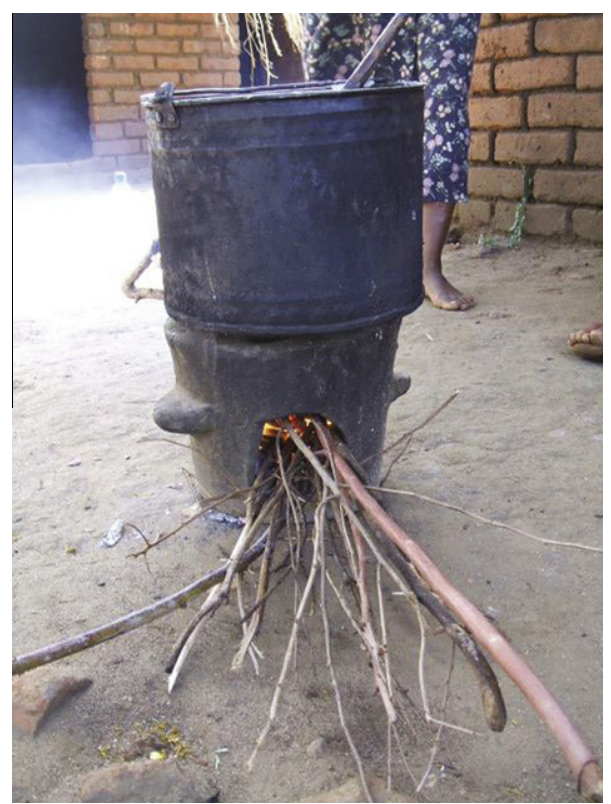

Fig. 1. The chitetezo mbuala in use in Balaka, Malawi. the households. For these reasons this stove was selected as the heat energy source for electrical energy production.

\section{Overview of thermoelectricity}

Thermoelectric generators, or TEGs, are solid state energy devices which convert heat directly into electricity by means of the thermoelectric effect. The thermoelectric effect is the result of a combination of other influences: the Seebeck effect, Thomson effect and Peltier effect, the Joule effect and the Fourier effect. TEGs have no moving parts and are commercially available in a variety of shapes, sizes and power ratings. The working principle is depicted in Fig. 2. A thermoelectric module is clamped between a heat source and a heat sink. Heat flows from the heat source through the module and is dissipated by the heat sink, and electricity is produced by the module. The thermoelectric module consists of pairs of $\mathrm{p}-\mathrm{n}$ thermoelements. The positive ( $\mathrm{p}$-type) and negative (n-type) doped semiconductor elements are connected electrically in series and thermally in parallel. Initially, the conductors in the module possess a uniform distribution of charge carriers. However, the heat input to the module, $Q_{H}$, creates a temperature difference across the $\mathrm{p}-\mathrm{n}$ thermoelements. The Seebeck effect is described by Rowe [21]. The free carriers at the hot end have greater kinetic energy and diffuse to the cold end. The accumulation of charge results in a back emf which resists further flow of charge. If the temperature difference across these junctions is maintained, an open circuit voltage $V_{o c}$ is generated according to

$V_{o c}=\alpha\left(T_{h}-T_{c}\right)$

where $\alpha$ is the Seebeck coefficient and $T_{h}$ and $T_{c}$ are the 'hot' and 'cold' junction temperatures. The Seebeck coefficient is a thermoelectric material property. Several thermoelectric materials are available for use in generators. Rowe [22] describes the 'worth' of thermoelectric materials, expressed by a quantity $Z$, known as the

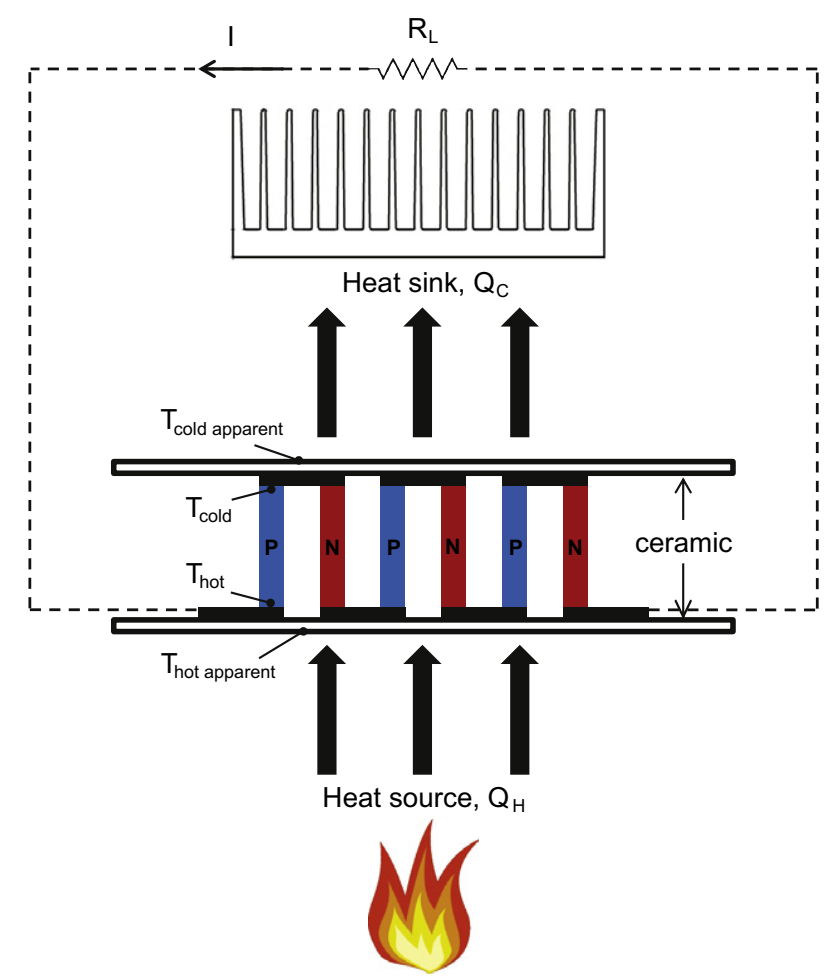

Fig. 2. Thermoelectric power generation. 
figure of merit. $Z$ depends on the thermal and electrical properties of the material and on the Seebeck coefficient, $\alpha$.

$Z=\frac{\alpha^{2} \sigma}{\lambda}=\frac{\alpha^{2}}{\rho \lambda}$

where $\lambda$ is the thermal conductivity, $\sigma$ the electrical conductivity, and $\rho$ is the electrical resistivity. The majority of thermoelectric generators in current use are based on bismuth-telluride $\left(\mathrm{Bi}_{2} \mathrm{Te}_{3}\right)$, lead-telluride ( $\mathrm{PbTe}$ ) or silicon-germanium (SiGe) alloy technologies. According to Rowe [22], $\mathrm{Bi}_{2} \mathrm{Te}_{3}$ generators have the greatest figure of merit, but are typically limited in their maximum operating temperature to approximately $250-300{ }^{\circ} \mathrm{C}$. PbTe and SiGe generators have lower figures of merit but compensate with the ability to operate at much higher temperatures $\left(\sim 600^{\circ} \mathrm{C}\right.$ for PbTe and $\sim 1000^{\circ} \mathrm{C}$ for $\mathrm{SiGe}$ ).

\subsection{Theoretical modelling of TEG performance}

A single thermocouple is depicted in Fig. 3. The electrical resistance $R$ and thermal conductance $K$ of a thermocouple of length $L$ and cross-sectional area $A_{p}$ are defined respectively as [23]:

$R=\frac{2 \rho L}{A_{p}}$

$K=\frac{2 \lambda A_{p}}{L}$

The equations used to model the behaviour of TEGs are based on the Seebeck, Fourier and Joule effects. Using the standard model [23] and assuming one dimensional conduction through the module, the rate of heat supply $Q_{H}$ and heat removal $Q_{C}$ can be estimated at the hot and cold junctions as

$Q_{H}=K(\Delta T)+\left(\alpha_{p, n}\right) I T_{h}-\frac{I^{2} R}{2}$

$Q_{c}=K(\Delta T)+\left(\alpha_{p, n}\right) I T_{c}+\frac{I^{2} R}{2}$

where $\alpha_{p, n}$ is equal to $\left(\alpha_{p}-\alpha_{n}\right)$, and $I$ is the current through the thermocouple. The electrical power generated by the TEG is given by the voltage and current across the external load, $R_{L}$. By applying an energy balance across the module, the electrical power, $P_{\text {elec }}$, is equal to the difference between heat delivered and dissipated, or $\left(Q_{H}-Q_{C}\right)$.

$P_{\text {elec }}=Q_{H}-Q_{C}=\alpha_{p n} I \Delta T-I^{2} R$

Dividing across by the current gives the voltage:

$V=\alpha_{p n} \Delta T-I R$

This gives voltage as a function of current for a given temperature difference. Using the standard model, the parameter $\alpha_{p n}$ is measured by open-circuiting $(I=0)$ the TEG, and measuring the applied temperature difference and corresponding voltage. By setting $P_{\text {elec }}$ equal to $I^{2} R_{L}$ in Eq. (7), the current can be found from

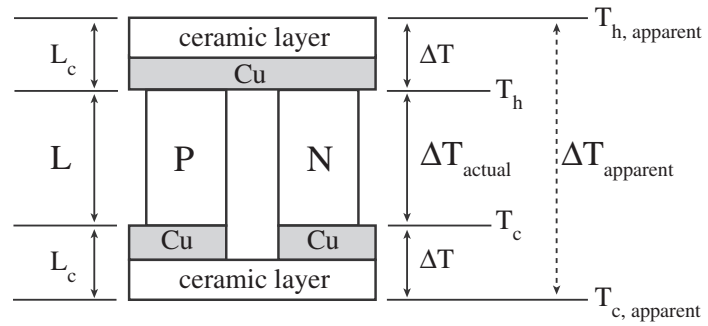

Fig. 3. Diagram of a single thermoelectric thermocouple.
$I=\frac{\alpha_{p n} \Delta T}{\left(R_{L}+R\right)}$

Substituting Eq. (9) into Eq. (7) yields an expression for the electrical power:

$P_{\text {elec }}=\left(\alpha_{p n} \Delta T\right)^{2} \frac{R_{L}}{\left(R_{L}+R\right)^{2}}$

A thermoelectric module generates maximum power when the module resistance matches the load resistance, i.e. when $R_{L}=R$ [24]. It follows that maximum power, $P_{\max }$, is given by

$P_{\max }=\frac{\left(\alpha_{p n} \Delta T\right)^{2}}{4 R}=\frac{A_{p}\left(\alpha_{p n} \Delta T\right)^{2}}{8 \rho L}$

From Eqs. (10) and (11), the power produced by each thermocouple is approximately proportional to its cross-sectional area, and inversely proportional to its length. Therefore, power produced by an entire module is dependent on the number of couples $N$ as well as the ratio of the load resistance to that of the TEG itself. Rowe and Min [25] developed a theoretical model which also took into account the thermal and electrical contact resistances across the ceramic and conductive strips, but this model requires detailed knowledge of the contact parameters and the physical properties of the $\mathrm{p}-\mathrm{n}$ pellets - information that is not always available from the manufacturer or supplier. For this study, an approach used by Hsu et al. [26] is utilised. This method, known as the effective Seebeck coefficient model, calculates the Seebeck coefficient under actual load conditions. This is necessary since the TEG performs differently under open-circuit and load settings. To calculate the effective Seebeck coefficient a fixed temperature difference is applied across the TEG and the load resistance is varied. For the TEG used in this study, Fig. 4 plots the voltage vs. the current for a range of temperature differences.

A linear relationship exists between the voltage and current. The 'effective' open-circuit voltage for each $\Delta T$ can be read from Fig. 4 by extrapolating the voltage corresponding to zero current ( $y$-axis intercept). Similar to Eq. (8), the approach of Hsu et al. relates the voltage to the current:

$V=\alpha_{p n} \Delta T-I R=A \Delta T-B I$

For the open-circuit voltage $(I=0), A \Delta T$ has a maximum value in which $A$ can be defined as the effective Seebeck coefficient, $\alpha_{\text {eff. }}$.

$\alpha_{\text {eff }}=\frac{V_{o c}}{\Delta T}$

The effective Seebeck coefficient specifies the TEG behaviour under actual load conditions, indirectly taking into account the contact effects such as interfacial temperature drops which are not measured in this study. This results in a Seebeck coefficient of lesser magnitude than the theoretical value for a given thermocouple. The power may be calculated from the following equation:

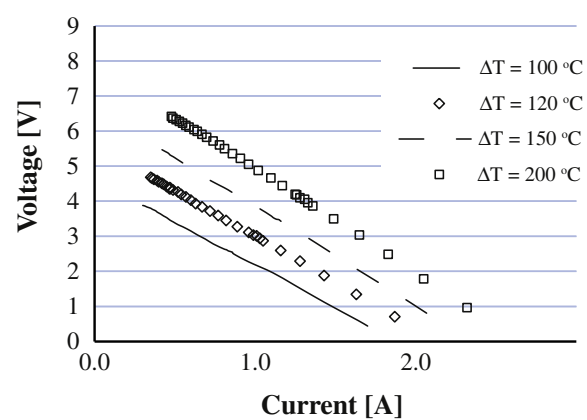

Fig. 4. Voltage vs. current for different $\Delta T$ for TEG1-12610-5.1. 


$$
P_{\text {elec }}=\left(\alpha_{\text {eff }} \Delta T\right)^{2} \frac{R_{L}}{\left(R_{L}+R\right)^{2}}
$$

\subsection{Thermoelectric module and battery selection}

The thermoelectric module produces power in response to a temperature difference between its 'hot' and 'cold' faces. Several thermoelectric models are available commercially. For this study, the chosen TEG 12610-5.1 is supplied by Thermal Electronics Corp., Canada. In low numbers, the unit cost of this module is approximately $\$ 49$, which reduces to $\$ 8$ in high volume ( $\sim 10,000$ units). According to the supplier's specification TEG1-12610-5.1 is capable of producing $5.9 \mathrm{~W}$ of electrical power at matched load. Some specifications for the module are provided in Table 1.

To investigate in detail the behaviour of the TEG under different operating conditions an experimental rig was constructed as shown in Fig. 5. The rig consists of a lower plate which is cooled by a water flow loop. The TEG sits on this surface. The upper surface is heated by cartridge heaters controlled by a variable power supply. The upper surface is lowered by a crank which enables the user to set the applied force on the TEG. The force is measured by a load cell which is connected to a digital high-accuracy multimetre. This TEG was subjected to a series of experiments to investigate the power generated in response to several parameters such as temperature difference, applied pressure, and load resistance. Fig. 6 plots the experimental data along with the theoretical predictions provided by the standard model (Eq. (10)) and the effective Seebeck coefficient model (Eq. (14)). Clearly, the effective Seebeck coefficient model predicts the TEG behaviour more accurately for the TEG used in this study.

The TEG is intended to be used as a power source to charge a rechargeable lithium-iron-phosphate $\left(\mathrm{LiFePo}_{4}\right)$ battery, specifically the ANR26650 cylindrical cell manufactured by $\mathrm{A} 123$ Systems. $\mathrm{LiFePo}_{4}$ batteries are known for their good safety characteristics and long life cycles. They can also be left in a partially discharged state for extended periods without causing permanent damage. Some battery specifications are provided in Table 2.

\section{Experimental design and apparatus}

\subsection{Heat collection and dissipation}

The side wall of the chitetezo mbaula stove has been selected to accommodate the generator. The TEG assembly consists of a $40 \mathrm{~mm} \times 40 \mathrm{~mm}$ TEG clamped between two $50 \mathrm{~mm} \times 50 \mathrm{~mm}$ copper plates, each $3 \mathrm{~mm}$ thick. By drilling holes to accommodate thermocouples, these plates allow the hot side and cold side TEG temperatures to be measured at roughly the same relative location and also provide a smooth surface for contact with the TEG. The plate on the hot side of the TEG is connected to a second copper plate, into which three $8 \mathrm{~mm}$ diameter copper rods are welded. These rods protrude into the centre of the stove, and deliver heat

Table 1

TEG1-12610-5.1 supplier specifications.

\begin{tabular}{ll} 
Dimensions & $40 \mathrm{~mm} \times 40 \mathrm{~mm}$ \\
Hot side temperature & $260^{\circ} \mathrm{C}$ \\
Cold side temperature & $50{ }^{\circ} \mathrm{C}$ \\
Open circuit voltage & $8.6 \mathrm{~V}$ \\
Internal electrical resistance & $3 \Omega$ \\
Match load output voltage & $4.2 \mathrm{~V}$ \\
Match load output current & $1.4 \mathrm{~A}$ \\
Match load output power & $5.9 \mathrm{~W}$ \\
Heat flow through the module & $\sim 140 \mathrm{~W}$ \\
Heat flux & $\sim 8.8 \mathrm{~W} / \mathrm{cm}^{2}$ \\
\hline
\end{tabular}

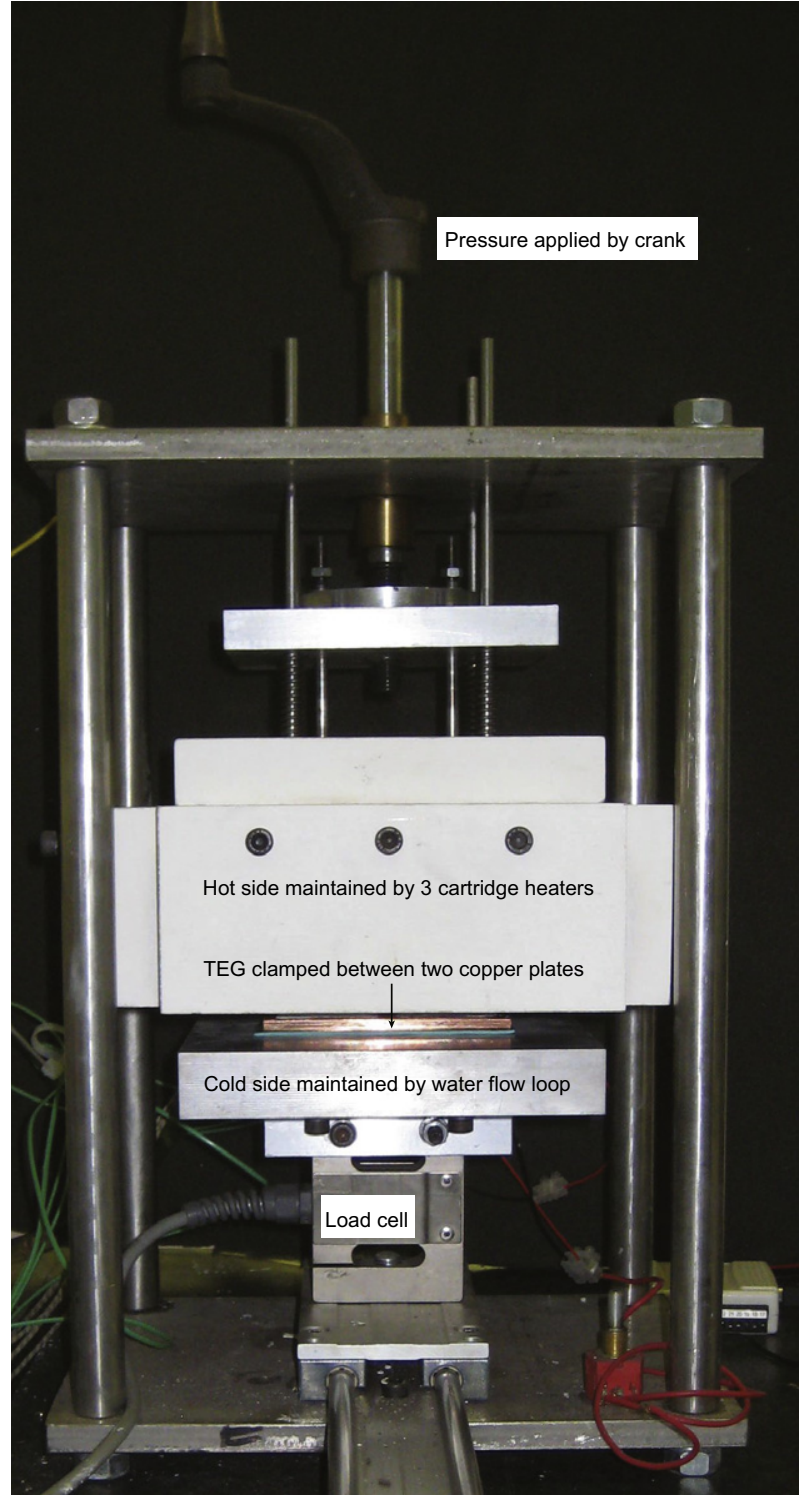

Fig. 5. TEG testing apparatus.

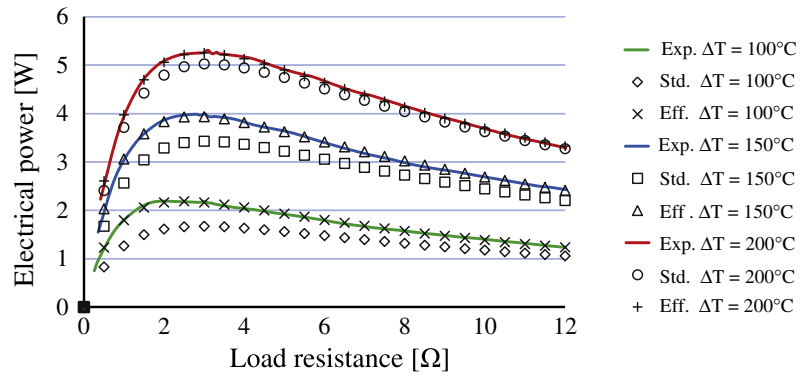

Fig. 6. Measured and predicted TEG performance using the standard model and the effective Seebeck coefficient model.

by conduction to the hot side of the TEG. The copper plates also receive heat by radiation from the fire. The thickness of the walls is such that removing a small section does not markedly weaken the stove. A sketch of the generator assembly is provided in Fig. 7 and the integration with the chitetezo stove is displayed in 
Table 2

$\mathrm{LiFePO}_{4}$ battery specifications.

$\begin{array}{ll}\text { Cell dimensions }(\mathrm{mm}) & \phi 26 \times 65 \\ \text { Cell weight }(\mathrm{g}) & 72 \\ \text { Cell capacity, nominal/minimum }(\mathrm{Ah}) & 2.3 / 2.2 \\ \text { Voltage, nominal }(\mathrm{V}) & 3.3 \\ \text { Internal impedance }(\mathrm{m} \Omega) & 8 \\ \text { Max. continuous discharge }(\mathrm{A}) & 70 \\ \text { Operating temperature }\left({ }^{\circ} \mathrm{C}\right) & -30-55 \\ \text { Typical cycle life } & >1000 \text { cycles }\end{array}$

Fig. 8. Thermal paste (Radionics SMT silicone heat sink compound) is used where applicable to minimise contact resistances.

The copper plate on the cold side of the TEG is thermally connected to an off-the-shelf CPU cooler (Arctic Cooling Freezer 13). This heat sink consists of four u-shaped $6 \mathrm{~mm}$ diameter copper heat pipes and 45 aluminium fins. The heat sink comes equipped with a $92 \mathrm{~mm} 12 \mathrm{~V}$ fan, but this fan requires over $2 \mathrm{~W}$ at full speed, which is large relative to the matched load power output of the TEG (roughly one third). At $12 \mathrm{~V}$ the heat sink has a maximum heat transfer capability of approximately $200 \mathrm{~W}$.

The cooling capacity of the fan is desired, but the power cost is too great. Instead, the $92 \mathrm{~mm}$ fan impeller is mounted to a low power DC motor (Manufacturer Mabuchi motors, model RF500 TB-14415) which is capable of driving the fan from voltages as low as $0.3 \mathrm{~V}$. This reduces the amount of power needed to drive the fan, but is still enough power to maintain the cold side at a reasonable temperature.

Since the TEG extracts heat from the stove and stove performance is not to deteriorate, a thin sheet-metal skirt is placed on the inside of the stove, as shown in Fig. 9. The skirt serves a dual purpose by preventing heat from escaping to the walls of the stove, and also by protecting the electrical connections of the TEG from the flames. The reduction in wall temperature due to the metal skirt can be seen in Fig. 10.

\subsection{Laboratory based battery charging circuitry}

The circuitry used to charge the lithium-iron-phosphate battery is quite simple, and has been specifically designed to be so. A circuit diagram is provided in Fig. 11. Several current sense resistors have been omitted for clarity. The TEG may be viewed as a DC power source. By measuring the voltage drop across the TEG and a $0.005 \Omega$ current sense resistor, the current and power produced by the TEG can be calculated.

The power produced by the TEG is primarily used to charge a $3.3 \mathrm{~V}$ lithium iron phosphate $\left(\mathrm{LiFePO}_{4}\right)$ battery, termed the 'primary' battery henceforth. A Schottky diode (Manufacturer STMicroelectronics, Mftr. Part \#STPS15L25D) prevents the battery from discharging to the TEG. The Schottky diode has a small voltage drop across it, and consumes up to $0.4 \mathrm{~W}$ at full TEG power.

To ensure a reasonable temperature difference across the TEG, some power must be used to drive the fan. The motor used to drive

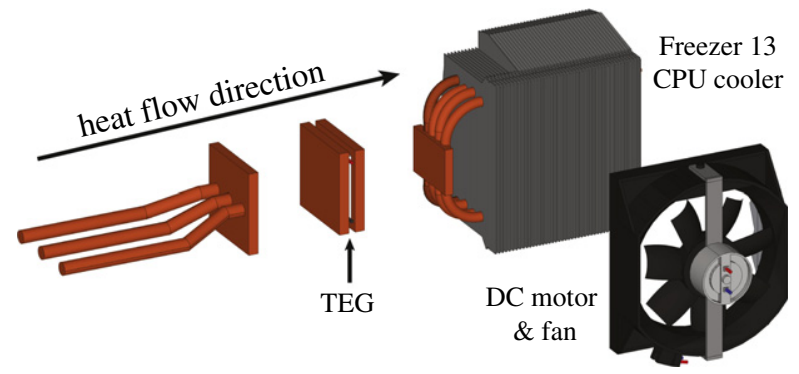

Fig. 7. Heat collection and dissipation design.
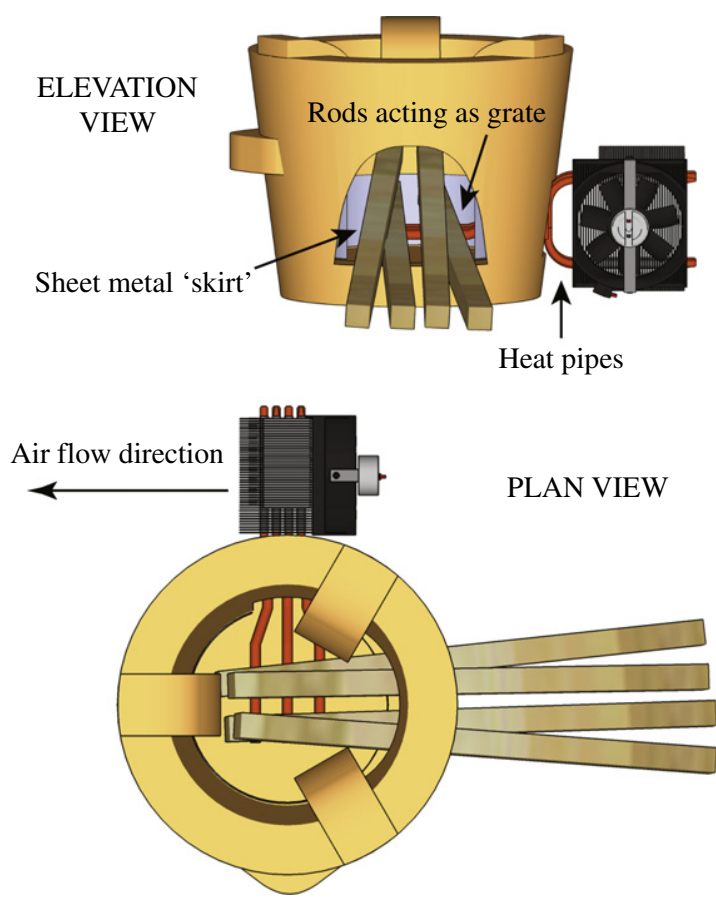

Fig. 8. Integration of generator with chitetezo mbaula.

the fan will start to spin even at very low voltages $(\sim 0.3 \mathrm{~V})$. The fan voltage remains within $2 \%$ of the TEG voltage throughout the experiment. A $4.3 \mathrm{~V}$ Zener diode prevents overcharging of the battery. When the voltage approaches $4.3 \mathrm{~V}$, the Zener allows some power to flow through it, until it opens completely and becomes the path of least resistance, effectively protecting the battery from further charging.

The battery is connected to a DC-DC converter (Texas instruments PTN04050CAD - IC, ISR $12 \mathrm{~W}, 4050$, DIL module-4), which boosts the output voltage to a more useful $5 \mathrm{~V}$, and is connected to a single male USB port. Fig. 12 plots the conversion efficiency for the DC-DC converter when charging a rechargeable LED lantern known as the Sun King. ${ }^{1}$ The conversion efficiency of the device, calculated as output power divided by input power, remains above $90 \%$ for the duration of the charge. The efficiency of the converter will depend on the type of device connected to the $5 \mathrm{~V}$ supply. For the devices tested in this study, the DC-DC converter efficiency is typically in the range $85-95 \%$.

The lithium-iron-phosphate battery has a nominal voltage of 3.3 V. When fully discharged, this voltage drops to approximately $2.2 \mathrm{~V}$. When placed in this circuit, the battery will charge until its voltage reaches $3.8 \mathrm{~V}$. The $5 \mathrm{~V}$ output from the converter is maintained whilst the primary battery voltage remains above $2 \mathrm{~V}$.

\subsection{Data acquisition}

Each generator stove is equipped with four data loggers: one for thermocouples, and three for voltage measurements. All data loggers are housed in a flame-retardant aluminium box (Camdenboss die-cast aluminium box, $192 \times 112 \times 61 \mathrm{~mm}$, IP65) which is mounted to the outside wall at the back of the stove. A sheet of metal is placed between the logger boxes and stove wall to prevent possible overheating of the data loggers due to radiation from the stove walls. A photograph of the logger box is provided in Fig. 13.

\footnotetext{
${ }^{1}$ http://www.greenlightplanet.com/products.html
} 

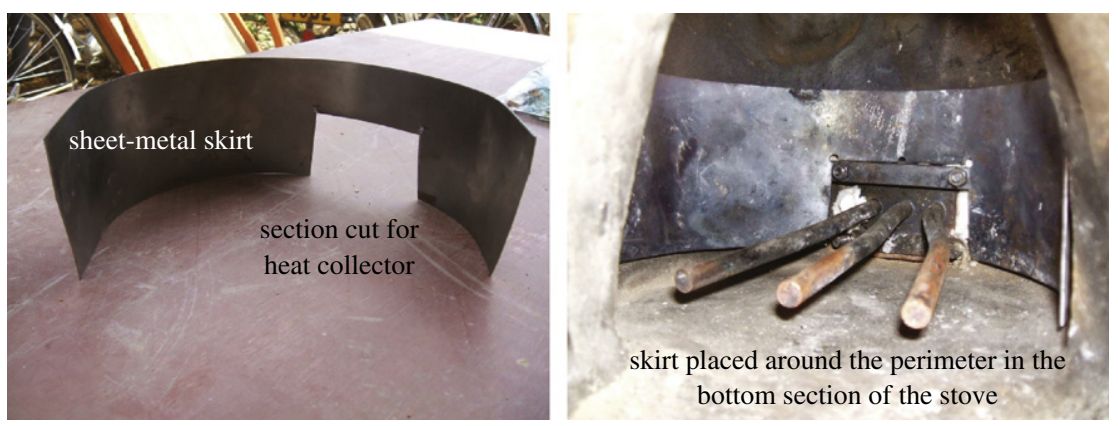

Fig. 9. Thin sheet-metal 'skirt' placed along the perimeter of the generator stove.

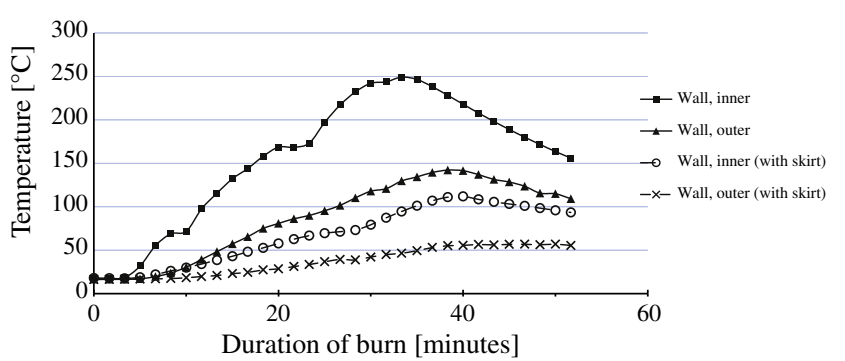

Fig. 10. Decrease in stove wall temperatures due to the introduction of a thin metal skirt.

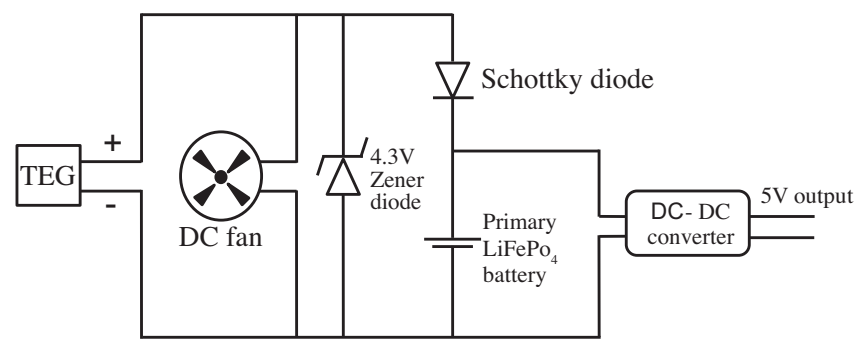

Fig. 11. Primary battery charging circuit (lab version).

The temperature at four selected locations is recorded at a rate of one reading per minute with a MadgeTech QuadTemp-EU 4 thermocouple data logger. The temperature on both sides of the thermoelectric generator is also recorded. From Eq. (10), the power generated is approximately proportional to the square of the temperature difference, and these temperatures will also offer insight into any possible failure mechanisms. The temperature $1 \mathrm{~cm}$ into the stove wall is also recorded, as well as the temperature in the combustion chamber. These temperatures will indicate when the stove is being used, and the length of time for which it is in use. The combustion chamber temperature may also offer some insight into the type of fuel used, though this information will likely be acquired through a survey of stove users. The QuadTemp logger also has four in-built ambient temperature sensors.

The voltage across the two current sense resistors is recorded using a MadgeTech Volt $101 \mathrm{~A} 0-160 \mathrm{mV}$ data logger. The small voltage drop across these $0.005 \Omega$ resistors enables calculation of the current flowing through the circuit and hence the power produced by the TEG. Furthermore, the current flow through the USB output is also recorded, which provides information on the power usage. The TEG voltage is recorded using a similar data logger configured to a voltage range of $0-15 \mathrm{~V}$. All data loggers can store up to 6 months of data at the selected recording rate of one reading per minute.

\section{Laboratory experimental results and discussion}

\subsection{Primary battery charging}

Typical results for a nominal $1 \mathrm{~h}$ long experiment performed at Trinity College Dublin are provided in Fig. 14. The temperature at four locations was measured using K-type thermocouples. In this experiment, a fire was lit and wood was added regularly to bring a saucepan containing initially $2.5 \mathrm{l}$ of water to the boil. Typically this took 25 min. Thereafter, the water was kept just below the boiling point for approximately $20 \mathrm{~min}$, after which the wood remaining in the stove was allowed to burn out.

As shown in Fig. 14a, the thermocouple placed inside the stove experiences a sharp rise in temperature once the fire is lit. Indeed, the temperature at the heart of the fire reaches almost $800^{\circ} \mathrm{C}$

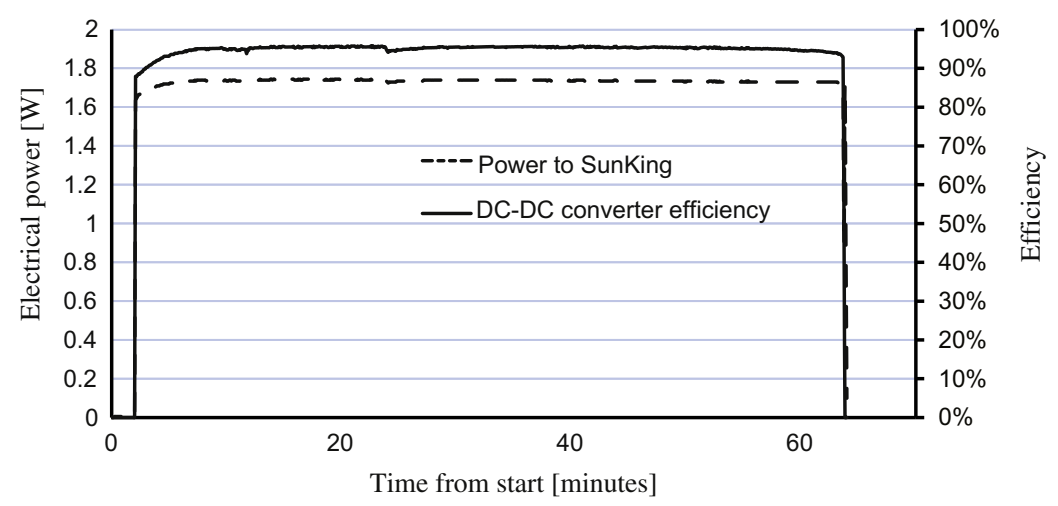

Fig. 12. Conversion efficiency of the Texas instruments DC-DC converter during Sun King LED light charging. 


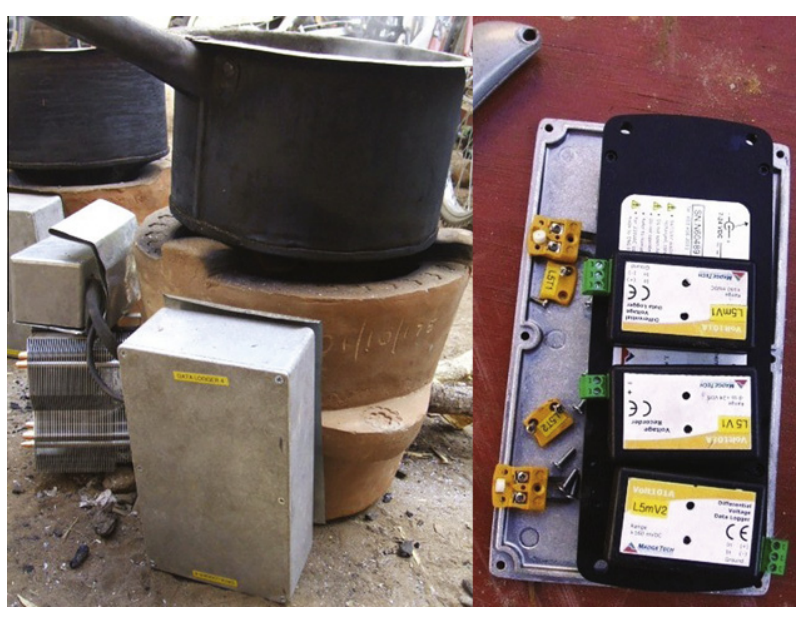

Fig. 13. Data loggers, enclosure and heat radiation shield.

during the burn. Since this thermocouple is exposed to the flames, the readings are somewhat erratic. However, it is evident that this measurement in particular allows one to determine when the fire was started, and the duration of the burn.

The ambient temperature was also recorded, and remained relatively stable at $19-20^{\circ} \mathrm{C}$ throughout the burn. Knowledge of the ambient temperature is important when interpreting the power produced by the TEG, since ambient air is drawn by the fan to cool the generator. It is predicted therefore, that the generator would perform better in a cooler climate.

Fig. 14b plots the power produced by the TEG, the power into the battery, and the sum of the power consumed by the other circuit components, $P_{\text {other }}$, given by

$P_{\text {other }}=P_{\text {fan }}+P_{\text {diode }}+P_{\text {zener }}+\sum P_{R_{\text {sense }}}$

A maximum TEG power output of $5.9 \mathrm{~W}$ was obtained, which is in agreement with the manufacturer's specifications. Clearly, the largest power output from the TEG corresponds to the point at which the temperature difference between the hot and cold side of the TEG is greatest.

To calculate the amount of electrical energy produced over the course of an experiment, the power curves are integrated mathematically. For the experiment depicted in Fig. 14 the TEG produced $3.9 \mathrm{~W}$ h of electrical power, of which $3.1 \mathrm{~W}$ h was stored in the battery. On average, approximately $3 \mathrm{~W}$ h of energy is stored in a battery during each $1 \mathrm{~h}$ long experiment. This equates to $9 \mathrm{~W}$ h over three separate hour long cooking periods. The battery has a nominal storage capacity of $8 \mathrm{~W}$ h. Therefore, $3 \mathrm{~h}$ long cooking periods should be sufficient to fully charge the primary battery, although this will depend heavily on ambient conditions and user operation of the stove.

\subsection{Primary battery discharging}

Several items may be connected to the battery to draw power. From the literature, and from discussions with persons working in the field, communications and light are of primary importance to rural communities in the developing world. The $5 \mathrm{~V}$ output is more useful as it is can be used to charge lights, phones, radios and more.

As a means of testing the capability of this generator prototype, several charging experiments were devised. The lithium-ironphosphate battery was fully charged over $3 \mathrm{~h}$ long burns in the stove. The battery was then connected to a commercially available Sun King LED lantern. The Sun King LED lantern can provide up to $16 \mathrm{~h}$ of light on a single day's charge. The lantern has three display modes:

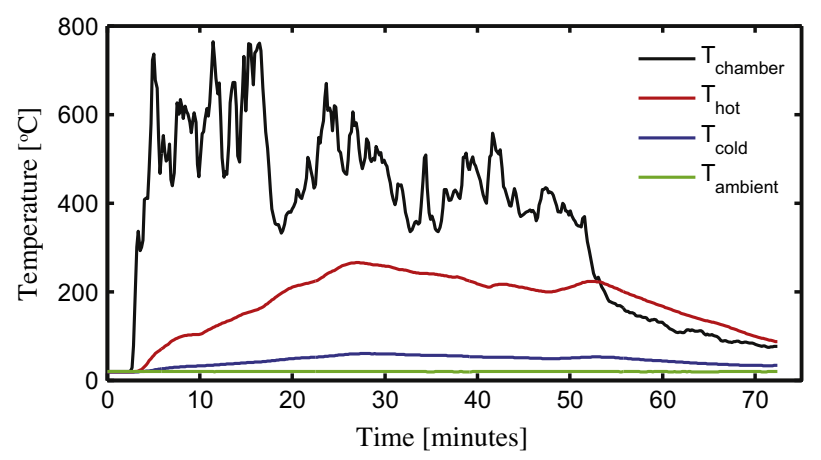

(a)

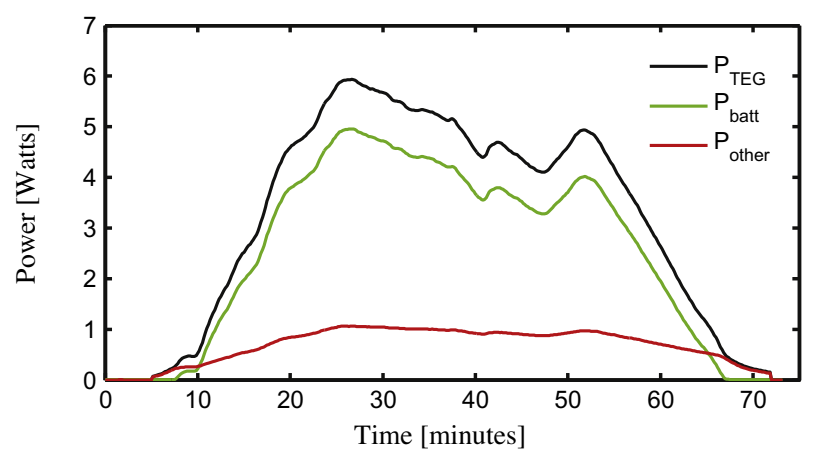

(b)

Fig. 14. Temperature and power profiles for the prototype stove.

(1) Turbo mode.

(2) Lantern mode.

(3) Spotlight mode.

Turbo mode has the highest intensity light. A fully charged Sun King can provide approximately $5 \mathrm{~h}$ of light at the highest intensity, at which point it automatically switches to the lantern setting to conserve power.

Fig. 15 shows the characteristics of the electrical appliance charging profiles where, for this scenario, the fully charged battery voltage is stepped up to $5 \mathrm{~V}$ and connected initially to a Sun King LED lantern. Once the Sun King was fully charged, any remaining power in the primary battery was to be used to charge a Nokia mobile phone. Fig. 15a plots the primary $\mathrm{LiFePo}_{4}$ battery voltage along with the voltage output from the DC-DC converter, and Fig. 14b plots the power provided by the primary battery and the power consumed by the load. From Fig. 15a, it is evident that the DCDC converter is capable of providing a consistent $5 \mathrm{~V}$ power supply to the LED light and mobile phone. From Fig. 15b, the Sun King drew $2 \mathrm{~W}$ at $5 \mathrm{~V}$ and was fully charged after $2 \mathrm{~h}$. It was calculated that the stove battery discharged almost $4 \mathrm{~W}$ h while charging the LED light. Since the battery is rated at approximately $8 \mathrm{Wh}$, some energy remained. Furthermore, the $\mathrm{LiFePO}_{4}$ battery voltage remained at $3.3 \mathrm{~V}$ indicating that there was energy available. The battery was then connected to a flat Nokia C102 mobile phone battery. Some specifications for this phone are provided in Table 3. In the initial charging period, the phone draws up to $5 \mathrm{~W}$. As the phone increases in charge level, it draws continually less power until after forty minutes the primary $\mathrm{LiFePO}_{4}$ battery voltage has dropped to $2.2 \mathrm{~V}$. At this point the primary battery is fully discharged. Importantly, charging ceases and the primary battery voltage does not drop below $2 \mathrm{~V}$.

The fully charged Sun King LED lantern was subjected to testing to measure how much light it could produce. Using a lux metre in 


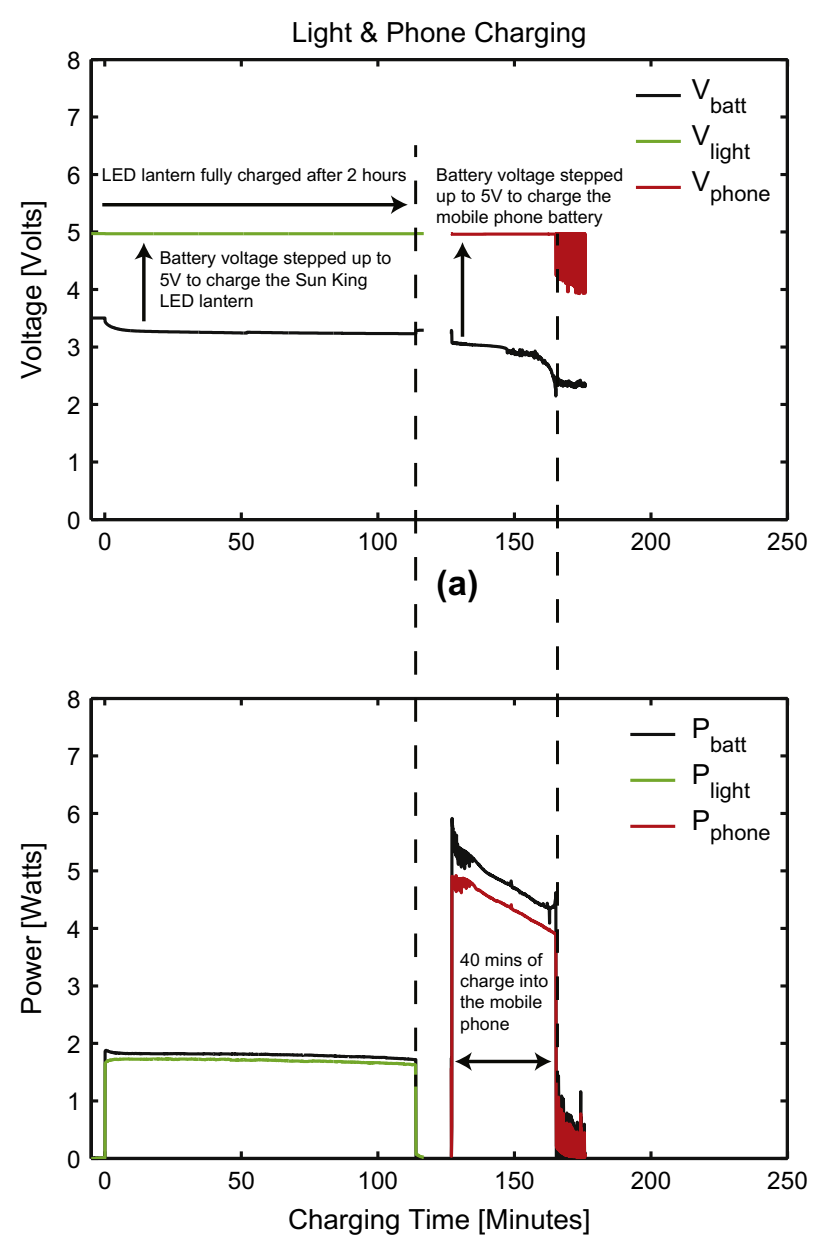

(b)

Fig. 15. Discharging the battery firstly into an LED lantern and then to a mobile phone.

Table 3

Nokia C102 mobile phone specifications.

\begin{tabular}{ll}
\hline Power management & Nokia Battery BL-5CB \\
& Talk time: Up to $10.6 \mathrm{~h}$ \\
& Standby time: Up to 21 days \\
& Bluetooth \\
Connectivity & $3.5 \mathrm{~mm}$ AV connector \\
& Full-Speed USB 2.0 (micro USB connector) \\
\end{tabular}

conjunction with some data logging equipment, the light was switched onto its most powerful setting and left in an otherwise dark room for several hours. The results of this test are provided in Fig. 16. The fully charged lantern was capable of delivering $5 \mathrm{~h}$ of its highest intensity light. After this period, the lantern self regulates to conserve power and switches to the 'Lantern' setting, a lower light intensity but still a huge improvement on total darkness. The lantern setting is maintained for a further $5 \mathrm{~h}$ before the lantern powers down.

The charging order was then reversed to further investigate the discharging behaviour of the stove battery. Again, the primary battery was fully charged over $3 \mathrm{~h}$ long burns in the stove, but when discharging, the mobile phone was charged first and any remaining charge was to be used to charge the LED lantern. In this scenario the mobile phone was fully charged after $105 \mathrm{~min}$. It was calculated that the stove battery discharged almost $5 \mathrm{~W}$ h while charg-

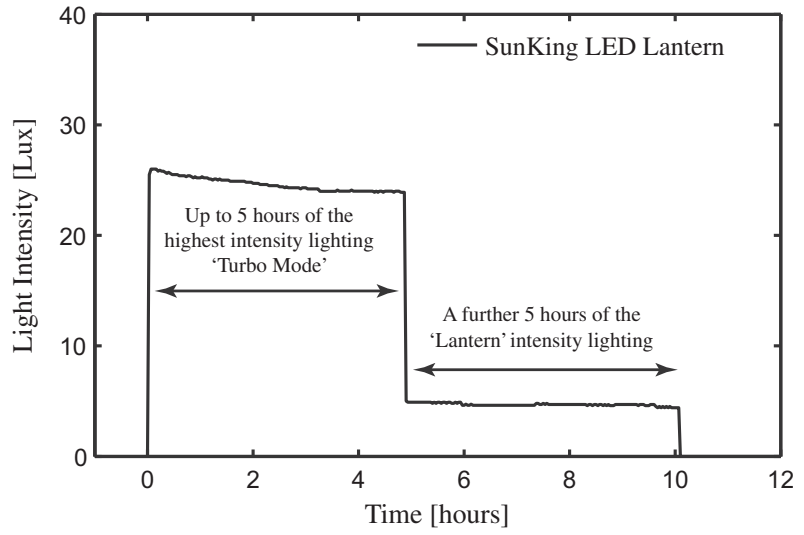

Fig. 16. Light intensity produced by the fully charged Sun King.

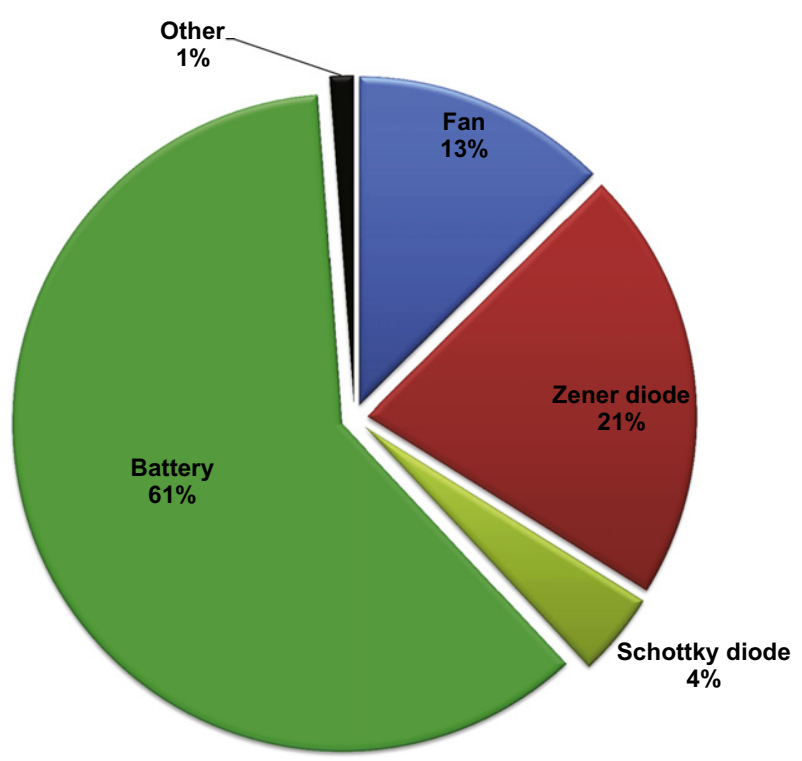

Fig. 17. Power consumption of circuit components during a typical burn in the chitetezo mbaula.

ing the mobile phone to full capacity. The remaining energy in the primary battery was then used to partially charge the LED lantern for $70 \mathrm{~min}$, which was sufficient to operate the turbo mode light setting for over $2 \frac{1}{2} \mathrm{~h}$, before the Sun King auto-regulated to the lantern setting for a further $5 \mathrm{~h}$ of light.

\section{Field design prototype}

\subsection{Field design circuit}

Some minor changes were made to the circuit before deployment in the field. During laboratory experiments, a $4.3 \mathrm{~V}$ Zener diode was used, which leaked current from voltages of $3.7 \mathrm{~V}$ upwards. Since the battery voltage at full charge is $3.8 \mathrm{~V}$, the $4.3 \mathrm{~V} \mathrm{Ze-}$ ner diode was removed and replaced by a $3.9 \mathrm{~V}$ version to provide a significant safety margin on battery overcharge. Unfortunately this also meant that some power is lost through the Zener before the battery is fully charged.

Another safety feature included in the field design is a thermal switch. The switch (Mulitcomp T23A070ASR20-15) allows current to flow through the battery until the battery temperature reaches 


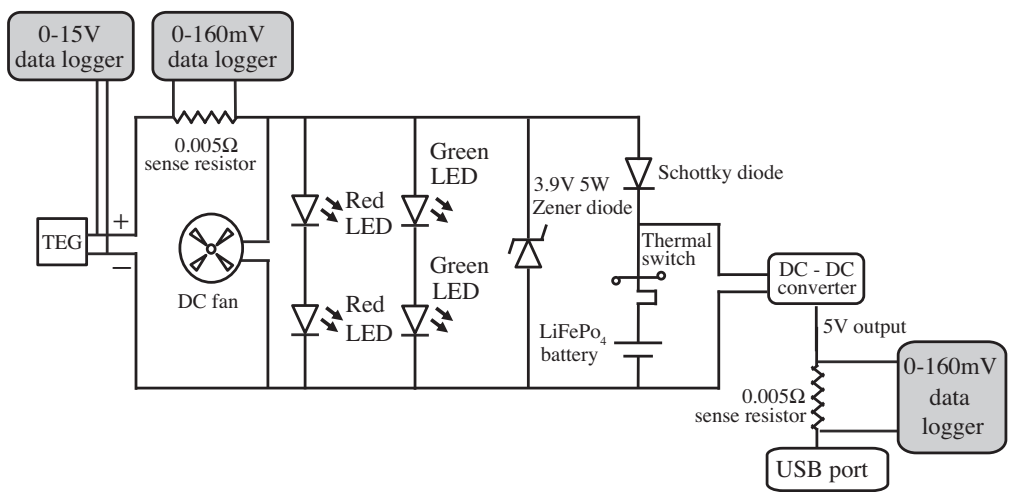

Fig. 18. Battery charging circuit (field version).

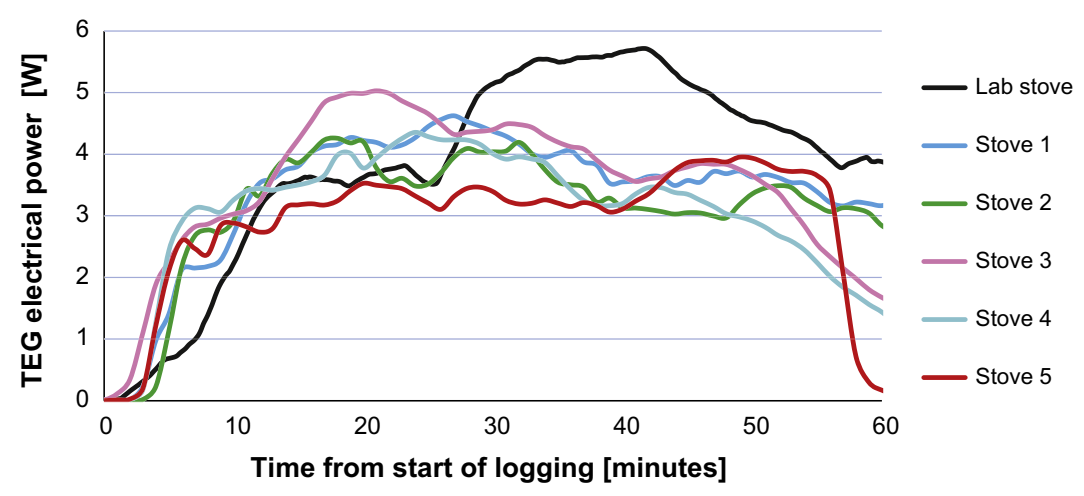

Fig. 19. Pre-deployment testing of generator stoves.

$70^{\circ} \mathrm{C}$, at which point the thermal switch opens and short-circuits the battery.

It was deemed prudent to have some form of indicator on the circuit box which would inform the user when the battery was charging, and when it was fully charged. To this end, two pairs of LEDs are included in the circuit, and installed on the front panel of the circuit box, facing the user as they operate the stove. Two red LEDs, each with a nominal forward voltage of $1.9 \mathrm{~V}$, indicate when the TEG voltage is sufficient to charge the battery. These LEDs typically become visible when $V_{T E G}$ is approximately $3.6 \mathrm{~V}$ and increase in brightness until $3.8 \mathrm{~V}$. At this point two green LEDs, each with a nominal forward voltage of $2 \mathrm{~V}$, will also become visible to indicate that the battery is fully charged. The LEDs are only visible when the stove is in use however.

The power consumption of the circuit elements during a typical burn in the chitetezo mbaula can be seen in Fig. 17. In this case approximately $60 \%$ of the generated power is stored in the battery, though this will depend on the initial charge level of the battery. The $3.9 \mathrm{~V}$ Zener diode consumes over $20 \%$ of power which is undesirable. Unfortunately this particular Zener leaks current from voltages as low as $3 \mathrm{~V}$.

The $5 \mathrm{~V}$ output from the DC-DC converter is connected to a single male USB port, which provides the user with the capability to easily connect a range of devices that charge from $5 \mathrm{~V}$ supplies. The field deign circuit is shown in Fig. 18.

\subsection{Pre-deployment field experiments}

All stoves were subjected to testing in Malawi prior to deployment in the villages. The inclusion of the generator was not found to have any detrimental effect on the structural integrity of the stove. It was also necessary to evaluate the performance of the generator stove in terms of power produced. Previous experiments

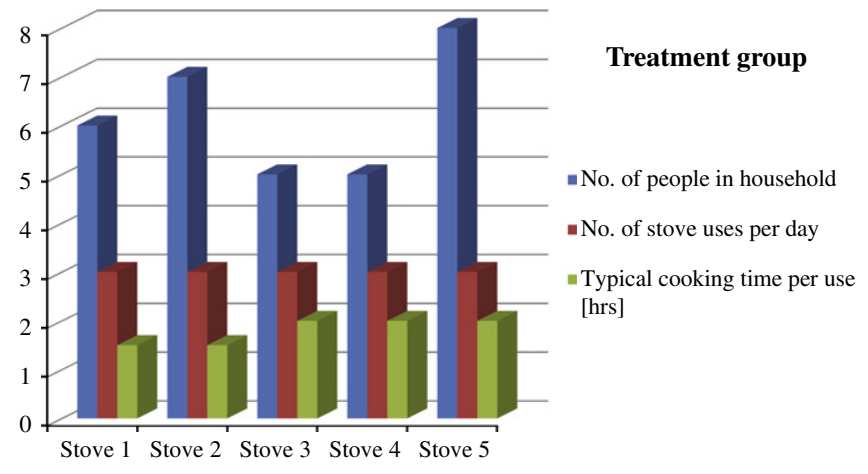

(a)

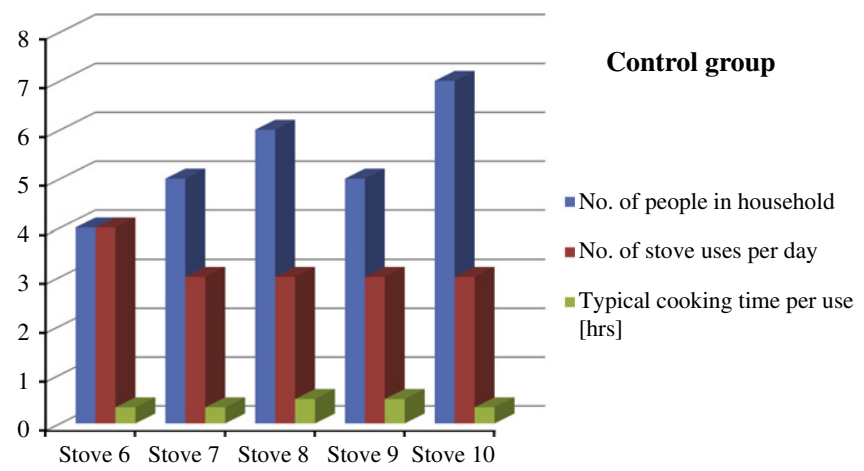

(b) 


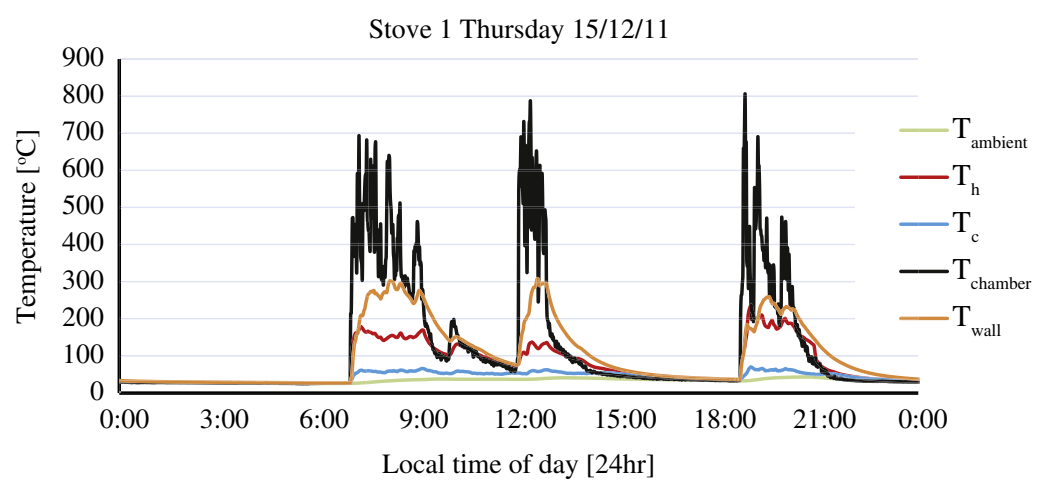

(a) Temperatures

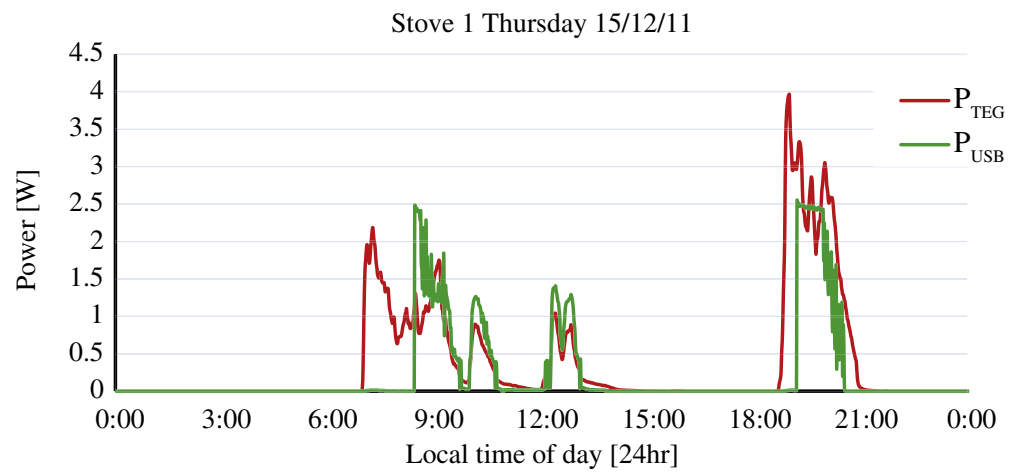

(b) Powers generated and consumed

Fig. 21. Stove 1 preliminary field results.

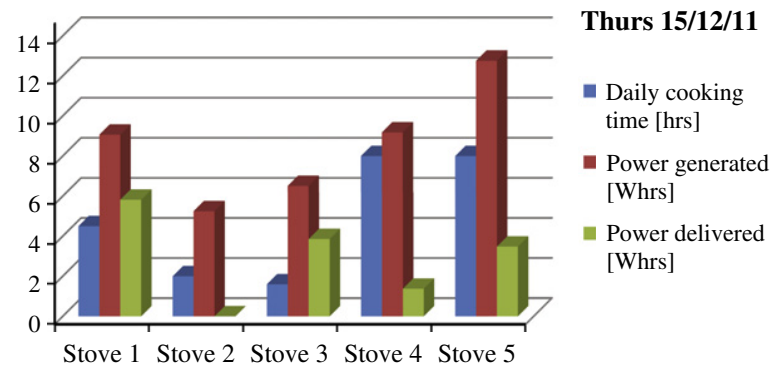

Fig. 22. Stove usage Thursday 15/12/11.

performed in Dublin suggested that if the generator stove was in use for a period of $1 \mathrm{~h}$, three times per day, enough electricity could be stored in the battery to fully charge a basic (Nokia) mobile phone and still have some energy remaining to partially charge a LED lantern.

In total, 5 generator stoves were constructed and tested. Fig. 19 shows a comparison of lab and pre-deployment field data for TEG power production. Compared with experiments performed in Ireland, the power generated in the field stoves is lower, but this was expected since the ambient temperature in Balaka in December was regularly in excess of $30^{\circ} \mathrm{C}$, which limits the cooling capacity of the fan and heat sink. Importantly, the stoves performed to a comparable level, and the charging circuitry worked as intended.

\subsection{Control E' treatment group surveys}

It was necessary to gather some information about the five participants who volunteered for the field trial. To this end, a brief survey of the participants was performed immediately prior to deployment of the stoves in the villages. Additionally, five participant families from a different village received non-generator stoves fitted with temperature data logging equipment. The five families given the generator stoves are termed the treatment group and the five families with the non-generator stoves are termed the control group. The survey was broken down into three sections: household information, stove information and questions relating to mobile phone and light usage. Some selected results are presented in Fig. 20.

There were some major differences between the two groups. Every participant from both groups said they used the stove three times per day, but the usage times for the treatment group were much longer. However, it was noted that some participants were unsure of their answers. It is expected that the data retrieved from the data loggers will elucidate the typical stove usage times.

All participants in the treatment group had at least one mobile phone, and used a variety of lighting methods such as candles and paraffin lamps. Many participants paid money to a local person to charge their mobile phone.

\subsection{Preliminary field results}

The five generator stoves were deployed in Malawi on Monday 12 th December in the village of Mponda, Balaka. The control group stoves were deployed 3 days later on Thursday 15th December in the village of Dulani. Some preliminary data was retrieved from the treatment group 4 days after deployment. Fig. 21 plots the data collected for Stove 1 on 1 day. From the temperature graph it can be seen that the stove was used in three separate periods. The duration of the cooking periods varies with the type of meal cooked and the number of people catered for. From the second figure, it would appear that the last meal of the day generated the most power. This burn also had the highest TEG temperature difference. 
The users of Stove 1 charged an appliance on four occasions on this particular day. The charging profile hints that the first device connected was a mobile phone, but the power was more than likely insufficient to fully charge the phone until the final burn of the day. It has been noted that the presence of large amounts of charcoal in the stove adversely affects power generation, since the charcoal insulates the TEG and prevents the hot side from reaching temperature close to its maximum operating point.

Data similar to that seen in Fig. 21 will be collected for each of the treatment and control group stoves in this study, and will be the subject of a subsequent article. Of the preliminary data obtained before departure from Malawi, Fig. 22 plots the stove usage information for Thursday 15th December 2011. Power generated refers to the TEG power produced, whereas power delivered refers to the power consumed by an appliance when connected to the USB port. Clearly, all stoves were used for several hours on this particular day. The day-to-day variance in stove usage over the first few days is high, but this is likely due to the fact that the generator stove is a new addition to the household and will therefore be a source of intrigue. It is hoped that after a bedding-in period the users will become accustomed to the generator stove and operate it as a normal chitetezo. Evidently, the users had connected various appliances to the stove to charge. On the return trip to obtain the preliminary data, the treatment group families explained that they had been charging the supplied LED lights, mobile phones and even radios from the stove. Some participants had even charged the phones of other members of the community.

The generator and non-generator stoves are to remain in the field for up to 3 months. It is envisaged that the large volume of data obtained on the stoves will offer valuable insight into user behaviour and the necessity for local off-grid power generation strategies for rural communities in the developing world.

\section{Conclusions}

A novel generator has been developed which is capable of producing small amounts of electrical power from a biomass-fed cookstove. The generator has been integrated into an existing cookstove used in Malawi. Under laboratory conditions, it has been shown that over $3 \mathrm{~h}$ long cooking periods in a single day, the generator is capable of producing up to $9 \mathrm{Wh}, 8 \mathrm{Wh}$ of which can be store in a battery. Five stoves have been equipped with the generator and deployed into a village in Balaka, Malawi. The stoves have been equipped with data logging capability and have been left in the field for a period of up to 3 months. Some preliminary data has been obtained which indicates that the stoves perform adequately in the field and provide the user with the ability to charge LED lights, mobile phones and radios from the generator stoves every day if necessary.

\section{Acknowledgements}

The authors would like to gratefully acknowledge Irish Aid, Electric Aid, Cara Malawi, The Irish Research Council for Science
\& Engineering Technology (IRCSET), Intel Corporation for their continued support and contribution to this research, and also Concern Universal for their continued assistance in the field.

\section{References}

[1] WHO. Fact sheet No. 292: indoor air pollution and health; 2011.

[2] OECD/IEA. Energy poverty: how to make modern energy access universal? 2010.

[3] Fullerton DG, Semple S, Kalambo F, Suseno A, Malamba R, Henderson G, et al. Biomass fuel use and indoor air pollution in homes in Malawi. Occup Environ Med 2009;66:777-83.

[4] WHO. Global health risks: mortality and burden of disease attributable to selected major risks; 2009.

[5] Mills E. The specter of fuel-based lighting. Science 2005;308(5726):1263-4.

[6] The Economist. Lighting up the world. Technology quarterly September 23 2006. <http://www.economist.com/node/7904248>.

[7] Irvine-Halliday D, Doluweera G, Platonova I, Irvine-Halliday J. SSL - A big step out of the poverty trap for the BOP! J Light Visual Environ 2008;32(2):258-66.

[8] Killander A, Bass JC. A stove-top generator for cold areas. In: Proceedings of the 15th international conference on thermoelectrics; 1996 Mar 26-29; New York, USA. New York: IEEE; 1996.

[9] Mastbergen D. Development and optimization of a stove-powered thermoelectric generator. Colorado State University; 2008.

[10] Champier D, Bedecarrats JP, Kousksou T, Rivaletto M, Strub F, Pignolet P. Study of a TE (thermoelectric) generator incorporated in a multifunction wood stove. Energy 2011;36:1518-26.

[11] Champier D, Bedecarrats JP, Rivaletto M, Strub F. Thermoelectric power generation from biomass cook stoves. Energy 2010;35:935-42.

[12] Eakburanawat J, Boonyaroonate I. Development of a thermoelectric batterycharger with microcontroller-based maximum power point tracking technique. Appl Energy 2006;83:687-704.

[13] Gou X, Xiao H, Yang S. Modeling, experimental study and optimization on lowtemperature waste heat thermoelectric generator system. Appl Energy 2010;87:3131-6.

[14] Hsu CT, Huang G-Y, Chu H-S, Yu B, Yao DJ. Experiments and simulations on low-temperature waste heat harvesting system by thermoelectric power generators. Appl Energy 2011;88:1291-7.

[15] Rinalde GF, Juanico LE, Taglialavore E, Gortari S, Molina MG. Development of thermoelectric generators for electrification of isolated rural homes. Int J Hydrogen Energy 2010;35:5818-22.

[16] Nuwayhid RY, Hamade R. Design and testing of a locally made loop-type thermosyphonic heat sink for stove-top thermoelectric generators. Renew Energy 2005;30:1101-16.

[17] Nuwayhid RY, Shihadeh A, Ghaddar N. Development and testing of a domestic woodstove thermoelectric generator with natural convection cooling. Energy Convers Manage 2005;46:1631-43.

[18] Warwick H, Doig A. Smoke - the killer in the kitchen. London: ITDG Publishing; 2004. p. 11.

[19] The Women's refugee commission. Sexual violence and firewood collection in Darfur; 2006. p. 40-1.

[20] Canadian medical association. Malawi health workers grapple with rising incidence of rape. Canad Med J 2009;181(12):279-280.

[21] Rowe DM. Thermoelectric power generation. Proc Inst Electr Eng 1978;125(11R):1113-6.

[22] Rowe DM. Thermoelectric generators as alternative sources of low power Renew Energy 1994;5:1470-8.

[23] Hodes M. On one-dimensional analysis of thermoelectric modules (TEMs) IEEE Trans Compon Packaging Technol 2005;28:218-29.

[24] Rowe DM, Min G. Evaluation of thermoelectric modules for power generation. J Power Sources 1998;73:193-8.

[25] Rowe DM, Min G. Design theory of thermoelectric modules for electrical power generation. IEE Proc Sci Meas Technol 1996;143:351-6.

[26] Hsu CT, Huang GY, Chu HS, Yu B, Yao DJ. An effective Seebeck coefficient obtained by experimental results of a thermoelectric generator module. Appl Energy 2011;88:5173-9. 